\title{
Utilization of bitumen modified with pet bottles as an alternative binder for the production of paving blocks
}

\section{T.F. Awolusi}

Afe Babalola University

D.o Oguntayo

Landmark University

O.E Babalola ( $\sim$ babalolaolusolaemmanuel.st@tdtu.edu.vn )

Ton Duc Thang University

\section{S.O Ajamu}

Ladoke Akintola University of Technology

\section{F.D Natie}

Landmark University

O Aladegboye

Landmark University

\section{Research Article}

Keywords: PET-modified bitumen, Paving blocks, Skid resistance, Compressive strength

Posted Date: August 5th, 2021

DOl: https://doi.org/10.21203/rs.3.rs-778007/v1

License: (9) (i) This work is licensed under a Creative Commons Attribution 4.0 International License. Read Full License 


\section{Abstract}

This study considers the utilization of bitumen modified with polyethylene terephthalate (PET) bottles waste as an alternative binder in paving blocks. The optimum bitumen content of asphalt concrete was modified with $2 \%, 4 \%, 6 \%, 8 \%$, and $10 \%$ of PET waste. The compressive strength test, skid resistance, water absorption, and abrasion test were conducted on the paving block samples. Compressive strength test was conducted to verify the samples' compressive strength performance while water absorption and abrasion test were used to ascertain the durability properties of the samples. Results obtained for PETmodified bitumen concrete paving blocks (PMBCB) show an increase in compressive strength, skid resistance, and a decrease in the water absorption and abrasion loss when compared to unmodified bitumen samples. The maximum compressive strength for the PET-modified bitumen concrete was recorded at $10 \%$ PET replacement level. This implies that the utilization of PET-modified bitumen as binders in concrete paving blocks will not only help in waste recycling but also contribute significantly to the protection and preservation of the environment.

\subsection{Introduction}

In recent years there has been an increasing tendency to recycle wastes generated by human activities through different effective solid waste management practices; Polyethylene terephthalate(PET), being one of the most common consumer plastics is used as a raw material for making materials such as bottles, containers for packaging food products and other consumer goods ${ }^{1}$. PET is the chemical name for polyester, it's a clear, strong, and lightweight plastic. Due to these exceptional properties, they have been widely used as high-impact resistant containers for foods and beverage packages, especially convenience-sized soft drinks, juices, and water ${ }^{2}$. Waste from PET bottles is particularly important as it constitutes a significant component of total solid waste generated ${ }^{3}$. This has been attributed to the fact that PET bottles are swiftly becoming the world's most preferred packaging material for drinks, foods, and beverages as several millions of them are produced globally ${ }^{4}$ and consequently posing a serious disposal problem ${ }^{5}$

Bitumen on the other hand is one of the oldest identified construction materials especially in road construction ${ }^{6}$. Other areas of bitumen application include roofing, pipe coating, environmental protection, electrical insulation, soundproofing, landslip containment, textiles, and medicine ${ }^{7}$. The engineering properties of bitumen to be used in any construction activities is very paramount and highly dependent on bitumen production and processing procedure ${ }^{8}$. It can be inferred that most available bitumen would not provide all the needed engineering characteristics for construction activities, hence, the need to improve it to meet specific required properties has been achieved by the addition of additives in literature 89 . This modification has been carried out to obtains softer blends at low service temperatures thereby reducing cracking ${ }^{10}$; obtain stiffer blends at high temperatures thus reduce rutting, reduce viscosity, increase stability and strength of mixtures ${ }^{11}$; improve resistance to abrasion and resistance to the 
fatigue of blends, oxidation and aging ${ }^{8}$; and to reduce the structural thickness and life costs of pavements ${ }^{12}$.

Several works have improved the properties of bitumen by using different types of additives and modifiers such as polymers, chemical modifiers, extenders, oxidants and antioxidants, hydrocarbons, and anti-stripping additives. Gopinath ${ }^{13}$ used modifiers to improve the rheological behaviour of bitumen, and they concluded that Polymer (PET)-modified bituminous binders offered better resistance against permanent deformations due to their higher phase angle and a higher softening point when compared to conventional binders. In the work of Ogundipe ${ }^{11}$, PET waste was used as a modifier for asphalt concrete, experimental results obtained using the Marshall test showed that the stability of modified asphalt concrete was reduced by $20.4 \%$ in comparison with the unmodified asphalt concrete; thereby indicating that PET waste could improve the permanent deformation resistance of bitumen. This is a good pointer that PET-modified bitumen could be used to obtain structural pavement blocks with good durability properties and at a very economical rate.

As a result of the environmental degradation posed by the disposal of PET bottles, this study intends to determine the applicability of PET-modified bitumen as binder in the production of paving blocks thereby providing effective PET bottle recycling measures as well as durable and economical production of paving blocks.

\subsection{Materials And Methods}

\subsection{Materials}

The following materials were used in this study.

\subsubsection{Cement}

Ordinary Portland cement (Dangote 3X brand, 42.5R grade) conforming to BS 12:1991 was used for preparing concrete mix.

\subsubsection{Aggregate}

The aggregate typed used was quarry dust. It is grey fine rock particles with maximum particle passing $4.75 \mathrm{~mm}$ sieve. The quarry dust used is dry in condition, thoroughly retained on $150 \mu \mathrm{m}$ aperture sieve size, and sourced locally at a granite quarry site in Omu-Aran, Kwara State. The physical properties of quarry dust used is presented in Table 1.

\subsubsection{Bitumen}

Bitumen of grade 50/70 was adopted for this research. It was sourced from a petroleum company. The properties of the bitumen is shown in Table 2 
Table 1: Physical properties of Quarry dust

\begin{tabular}{lll} 
S/N & Physical Properties & Quarry dust \\
\hline 1 & Specific gravity & 2.70 \\
\hline 2 & Fineness modulus & 2.85 \\
\hline 3 & Bulk Density $\left(\mathrm{kg} / \mathrm{m}^{3}\right)$ & 1780 \\
\hline 4 & Fine particles less than $0.0075 \mathrm{~mm}(\%)$ & 13
\end{tabular}

Table 2: Bitumen properties

\begin{tabular}{|llll|}
\hline PARAMETERS & VALUE & SPECIFICATION & STANDARD \\
\hline Penetration @25ㅇ & 66 & $60-70$ & AASTHO D-5 \\
\hline Ductility @ $25^{\circ} \mathrm{C}$ & 121 & $100 \mathrm{Min}$ & AASTHO D-113 \\
\hline Solubility & 107 & $99.5 \mathrm{Min}$ & AASTHO D-4 \\
\hline Viscosity (cP) & 2753 & $2400 \mathrm{Min}$ & ASTM D-2171 \\
\hline Flash Point $\left({ }^{\circ} \mathrm{C}\right)$ & 287 & $\geq 250$ & ASTM D-70 \\
\hline Softening Point $\left({ }^{\circ} \mathrm{C}\right)$ & 56 & $55-65$ & ASTM D36 \\
\hline Specific gravity @ 25ㄷ & 1.04 & $1.01-1.06$ & ASTM D-92 \\
\hline
\end{tabular}

\subsubsection{PET bottles}

The polymeric materials used for modification were waste polyethylene terephthalate (PET) bottles collected within Landmark University campus (see Figure 1). The labels on the bottles were removed and the bottles were then washed and air-dried to enable easy melting

\subsection{Mix Proportions}

The mix proportion used for laboratory work is shown in Table 3. The optimum bitumen content of the bituminous concrete was modified with $2 \%, 4 \%, 6 \%, 8 \%$, and $10 \%$ of molten PET bottles to determine their effect at different modification levels.

Table 3: Specimen mix proportion 


\begin{tabular}{|llllll|}
\hline Mix ID & $\%$ PET replacement & Bitumen $(\mathrm{g})$ & PET $(\mathrm{g})$ & Cement(g) & Quarry dust $(\mathrm{g})$ \\
\hline C100 & 0 & 0 & 0 & 342 & 2048 \\
\hline B100 & 0 & 4,608 & 0 & 0 & 2048 \\
\hline PMB-2 & $2 \%$ & 3,724 & 76 & 0 & 2048 \\
\hline PMB-4 & $4 \%$ & 3,648 & 152 & 0 & 2048 \\
\hline PMB-6 & $6 \%$ & 3,572 & 228 & 0 & 2048 \\
\hline PMB-8 & $8 \%$ & 3,496 & 304 & 0 & 2048 \\
\hline PMB-10 & $10 \%$ & 3,420 & 380 & 0 & 2048 \\
\hline
\end{tabular}

Remark: Mix ID: C100, is 100\% Cement base concrete paving block; B100, is unmodified bitumen paving blocks; and PMB-a, PMB = PET modified bitumen paving blocks - while ' $a$ ' is the percentage replacement of bitumen with PET.

\subsection{Laboratory Test}

\subsubsection{Compressive Strength}

The compressive strength of the samples was measured at 7, 14, and 28days according to ASTM C39/C39M-09a, using the Universal Testing Machine (see Figure 2). The compressive strength tests are done in whole units of sample blocks, and the value is taken as the quotient of the maximum test load (until rupture) and the cross-section of the specimen tested ${ }^{14}$.

\subsubsection{Water Absorption}

Water absorption test was conducted to determine the amount of water absorbed under specified conditions in accordance with British Standard ${ }^{15}$. The paving block samples after 28 days were ovendried at a temperature of $105^{\circ} \mathrm{C}$ for 6 hours. The oven-dry weight of the paving block was measured and subsequently wholly immersed in water for 24 hours. The weight after water immersion is also measured.

\subsubsection{Skid Resistance}

The skid resistance of the samples was measured using the Portable Skid Resistance Tester (British Pendulum tester) shown in Figure 3 in accordance with British Standard ${ }^{16}$. The pendulum released from the horizontal position hit the surface and the needle position indicates reading of the pointer to the nearest whole number ${ }^{17}$. This approach focus on the pavement surface microtexture which refers to the small-scale texture of the pavement aggregate component that controls contact between the tire rubber and the pavement surface ${ }^{18}$. Three (3) runs of British pendulum tester (BPT) were conducted over each of 
the samples produced and the mean value is recorded. Before running the BPT, A 24-hour curing period was taken into account and the surface was properly wet as per wet condition specifications.

\subsubsection{Cantabro loss}

The Cantabro abrasion resistance test was carried out on the specimen using Los Angeles abrasion (LAA) testing machine in accordance with ASTM standard ${ }^{19}$. Durability is a vital requirement of any type of pavement surface. Hence, it is imperative that the loss of particles on bitumen pavement surface when subjected to abrasive load be minimum for structural reliability ${ }^{20}$. In this test, each sample of the paving block was placed in LAA machine. The initial weight of each specimen is measured ( ) and recorded before placing it into the machine. The LAA machine was allowed to rotate at a speed of 30-33 revolutions per minute for 300 revolutions. After the revolution, the abraded sample (see Figure 4) was cleaned from any loose rubbles and weigh( ).Equation 1 is used to compute the abrassion loss.

$$
\text { Cantabro Loss }(\%)=\frac{\left(\mathrm{W}_{1}-\mathrm{W}_{2}\right)}{\mathrm{W} 1} \times 100(1)
$$

\section{Where: $w_{1}=$ Initial weight of the sample in grams ' $\mathrm{g}$ '}

\section{$w_{2}=$ Final weight of the sample in grams ' $\mathrm{g}$ '}

\subsection{Results And Discussion}

\subsection{Compressive Strength}

Figure 5 presents the compressive strength results of the cement and PET-modified bitumen paving blocks. As expected, the compressive strength increases with curing days in the range of 8.18 to $17 \mathrm{Nmm}^{-}$ $2,11.67$ to $20.49 \mathrm{Nmm}^{-2}$, and 11.78 to $23.64 \mathrm{Nmm}^{-2}$ for 7,14 , and 28 -days curing period respectively. Considering the different mix of paving blocks used in this study, those with cement binder have the highest compressive strength; indicating that bitumen and PET-modified bitumen binder do not significantly improve the compressive strength. The reduction unmodified and PET-modified paving block compressive strength compared to cement binder pavement block is attributed to the development of a weaker interfacial transition zone (ITZ) formed at the interface of bitumen binder and aggregates. However, PET-modified paving blocks show increased compressive strength compared to unmodified Bitumen paving block samples. According to Udawattha ${ }^{21}$, the minimum strength requirement for 'class 4 ' for use of pedestrian walkways is $15 \mathrm{~N} / \mathrm{mm}^{2}$, therefore, the pavement block produced with $10 \%$ PETmodified bitumen with curing period of 28-days is suited for the construction of pedestrian pavement.

A one-way analysis of variances (ANOVA) was performed to determine if the effect of curing age and percentage of PET bottles on the compressive strength is significant or not. The results of the ANOVA analysis for the relationship between Compressive strength, curing age and percentage of PET bottles are summarized in Table 4. As seen from Table 4, the statistical p-value computed is 1.0805E-6; hence, it can 
be concluded that the influence of curing age and percentage of PET bottles on the compressive strength is significant.

Table 4: ANOVA analysis for the relationship between Compressive strength, curing age and percentage of PET bottles.

\begin{tabular}{|llllll|}
\hline Source & DF & Sum of Squares & Mean Square & F-Value & Prob>F \\
\hline Model & 2 & 1175.00083 & 587.50042 & 18.20345 & $1.0805 E-6$ \\
\hline Error & 51 & 1645.98005 & 32.27412 & & \\
\hline Total & 53 & 2820.98088 & & & \\
\hline
\end{tabular}

\subsection{Water Absorption}

Moisture damage of pavements is a significant problem affecting the durability of pavements. The amount of water absorbed for each paving block sample is shown in Figure 6. There is an observed decrease in water absorption with increasing PET contents in paving blocks. The water absorption decreases by about $56 \%$ while considering the value obtained for unmodified bitumen paving block (7.2\%) to that with $10 \%$ PET modified bitumen (3.2\%). Hence, PET addition significantly reduces the affinity of bitumen paving blocks to water as observed in paving block sample PMB-10 having the lowest water absorption value. This can be attributed to the good water-repellant characteristics of PET due to its hydrophobic properties ${ }^{22}$. The low water absorption characteristics exhibited by the PET-modified bitumen is key to ensure that the mixture is protected from moisture damage during the service stage.

\subsection{Skid Resistance}

The skid resistance value measured for samples is shown in Figure 7. Skid resistance is quantified using a skid number (SN) which measures the ratio of frictional resistance to motion in plane of interface ' $\mathrm{F}$ ' to load perpendicular to interface 'L'(the higher the SN, the better). TRRL Road Note $27{ }^{23}$. Among all samples tested, the $2 \%$ PET-modified bitumen samples had the lowest skid numberof 34 while $6 \%$ PETmodified bitumen sample has the highest skid number of 85 . Also, samples with $4 \%$ PET-modified bitumen contributed the least skid resistance with only $0.1 \%$ increase in skid number when compared to unmodified bitumen samples while both $8 \%$ and $10 \%$ PET-modified bitumen contributed $64.71 \%$ skid number to the samples. This indicates an improved skid resistance in bitumen pavement blocks modified with PET. All tested samples meet the Category $\mathrm{C}$ minimum skid resistance value (45) based on TRRL Road Note 27 specification ${ }^{24}$, except samples having $2 \%$ PET-modified bitumen which has a reduced SN of 33.34. However, a lower level of skid resistance offered by the $2 \%$ PET-modified bitumen may be acceptable in some residential streets depending on its geometry and traffic conditions.

\subsection{Cantabro Abrasion Loss}


The Cantabro test was used to evaluate the particle loss of the specimen and the result obtained is shown in Figure 8. The effect of various binder compositions on the abrasion loss showed a decreasing trend of abrasion value with increasing PET content. The correlation between compressive strength and Cantabro loss of the paving block is presented in Figure 9. The Cantabro loss demonstrated a clear negative linear relationship with compressive strength. This is attributed to enhanced binder characteristics and aggregate packing force of aggregates within PET-modified bitumen paving block resulting in enhanced compressive strength and less abrasion loss. This result is also in agreement with 20 and ${ }^{25}$.

\subsection{Conclusion And Recommendation}

One way to reduce the cost of road construction and rendering it more sustainable is by utilization of waste materials. This study considers using bitumen modified with polyethylene terephthalate (PET) waste as an alternative binder in paving block. The experimental results have demonstrated significant performance in terms of skid resistance, compressive strength, and abrasion loss. Based on the experimental investigation, the following conclusions are drawn:

1. PET-modified bitumen is found to have the highest skid number indicating that PET can significantly improve the skid resistance of paving blocks.

2. The utilization of unmodified bitumen in paving block reduces its compressive strength, however, PET-modified paving blocks show increased compressive strength compared to unmodified Bitumen paving block samples. The highest compressive strength is obtained at $10 \%$ PET modified bitumen level.

3. Abrasion loss decreases with increasing PET content. A clear negative correlation is obtained between abrasion loss and compressive strength which further confirms that PET modified bitumen pavement block will perform well in term of durability and strength requirement.

4. There was significant reduction in water absorption with increasing PET contents. This is important as it will ensure that the paving block is protected from moisture damage during its service stage, hence enhanced durability performance.

\section{References}

1. Chacon, F. A., Brouwer, M. T. \& van Velzen, E. U. T. Effect of recycled content and rPET quality on the properties of PET bottles, part I: Optical and mechanical properties.Packag. Technol. Sci.(2020).

2. Zhang, R. et al. PET bottles recycling in China: An LCA coupled with LCC case study of blanket production made of waste PET bottles.J. Environ. Manag. Elsevier(2020).

3. Taaffe, J., O'Sullivan, S., Rahman, M. E. \& Pakrashi, V. Experimental characterisation of Polyethylene Terephthalate (PET) bottle Eco-bricks. Mater. Des, 60, 50-56 (2014).

4. Papong, S. et al. Comparative assessment of the environmental profile of PLA and PET drinking water bottles from a life cycle perspective. J. Clean. Prod, 65, 539-550 (2014). 
5. Leng, Z., Padhan, R. K. \& Sreeram, A. Production of a sustainable paving material through chemical recycling of waste PET into crumb rubber modified asphalt. J. Clean. Prod, 180, 682-688 (2018).

6. Zhu, J., Birgisson, B. \& Kringos, N. Polymer modification of bitumen: Advances and challenges. Eur. Polym. J, 54, 18-38 (2014).

7. Muritala, K. B. \& Adewole, J. K. Development of Nigeria's bitumen for National economic growth: Opportunities for membrane separation technology. NSChE J, 32, 96 (2017).

8. Porto, M. et al. Bitumen and bitumen modification: A review on latest advances. Appl. Sci, 9, 742 (2019).

9. Remišová, E. \& Holý, M. Changes of properties of bitumen binders by additives application. IOP Conf. Ser. Mater. Sci. Eng, 245, 32003 (2017).

10. Lewandowski, L. H. Polymer modification of paving asphalt binders. Rubber Chem. Technol, 67, 447-480 (1994).

11. Ogundipe, O. M. The Use of Polyethylene Terephthalate Waste for Modifying Asphalt Concrete Using the Marshall Test. Slovak J. Civ. Eng, 27, 9-15 (2019).

12. Honarmand, M., Tanzadeh, J. \& Beiranvand, M. Bitumen and its modifier for use in pavement engineering. in Sustainable Construction and Building Materials (IntechOpen, 2019).

13. Gopinath, P. \& Kumar, C. N. Performance evaluation of HMAC mixes produced with gilsonite modified bitumen for heavily trafficked roads. Mater. Today Proc.(2020).

14. Alconpat, R. Compressive strength in concrete paving blocks. Results leading to validate the test in half-unit specimens. ALCONPAT Int, 3, 247-261 (2017).

15. BS 1881 - 122. Testing Concrete-Part 122: Method for Determination of Water Absorption. (1998).

16. BS 812: Part 114. Testing Aggregate" Method For Determination of Polished-Stone Value.Br. Stand. Inst.(1989).

17. Hafeez, I., Kamal, M. A., Riaz, K. \& Khan, M. I. A Laboratory Experimentation Based Ranking of Margalla Crush Aggregates. Tech. Journal, Univ. Eng. Technol. Taxila, Pakistan, 20, 62-67 (2015).

18. Corley-Lay, J. B. Friction and surface texture characterization of 14 pavement test sections in Greenville, North Carolina. Transp. Res. Rec, 1639, 155-161 (1998).

19. ASTM C1747/C1747M-13. ASTM International, West Conshohocken, PA (Taylor \& Francis, 2013). Standard test method for determining potential resistance to degradation of pervious concrete by impact and abrasion

20. Saboo, N., Prasad, A. N., Sukhija, M., Chaudhary, M. \& Chandrappa, A. K. Effect of the use of recycled asphalt pavement (RAP) aggregates on the performance of pervious paver blocks (PPB). Constr. Build. Mater, 262, 120581 (2020).

21. Udawattha, C., Galabada, H. \& Halwatura, R. Mud concrete paving block for pedestrian pavements. Case Stud. Constr. Mater, 7, 249-262 (2017).

22. Jasmee, S. et al. Hydrophobicity performance of polyethylene terephthalate (PET) and thermoplastic polyurethane (TPU) with thermal effect. Mater. Res. Express, 5, 96304 (2018). 
23. RD/GN/009. Guidance notes on road testing. Highw. Dep. Res. Dev. Div.(1989).

24. Hosking, R. Road Aggregates and Skidding. TRL State of the Art Review No 4.Transp. Res. Lab. Her Majesty's Station. Off. London(1992).

25. Rao, S. K., Sravana, P. \& Rao, T. C. Abrasion resistance and mechanical properties of Roller Compacted Concrete with GGBS. Constr. Build. Mater, 114, 925-933 (2016).

\section{Figures}
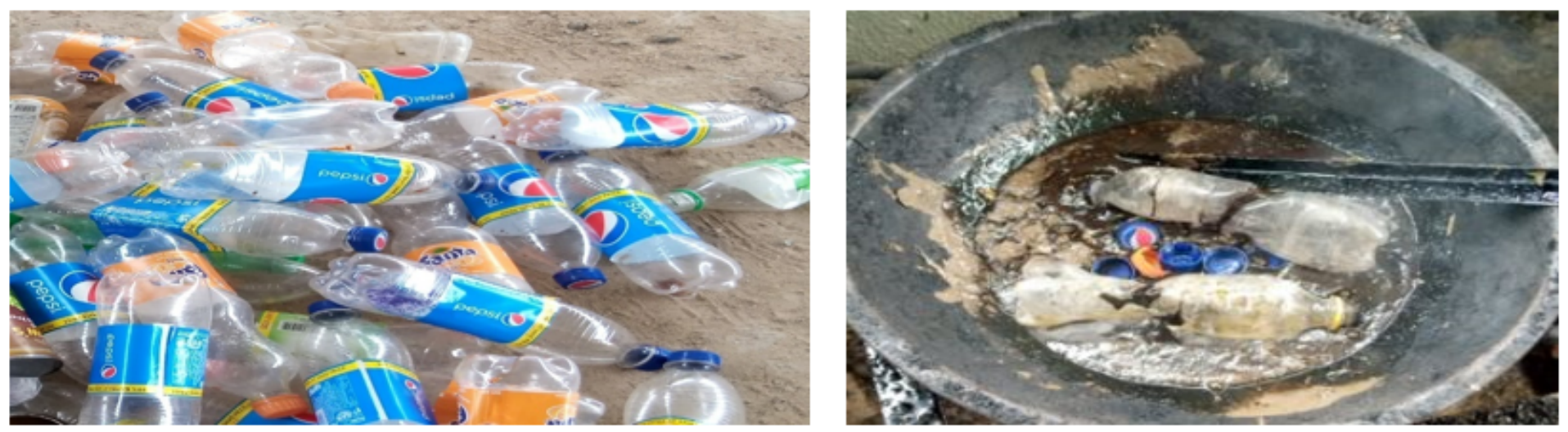

(a)

(b)

\section{Figure 1}

Waste PET bottles (a) Samples of collected waste PET bottles (b) Melting process of PET bottles

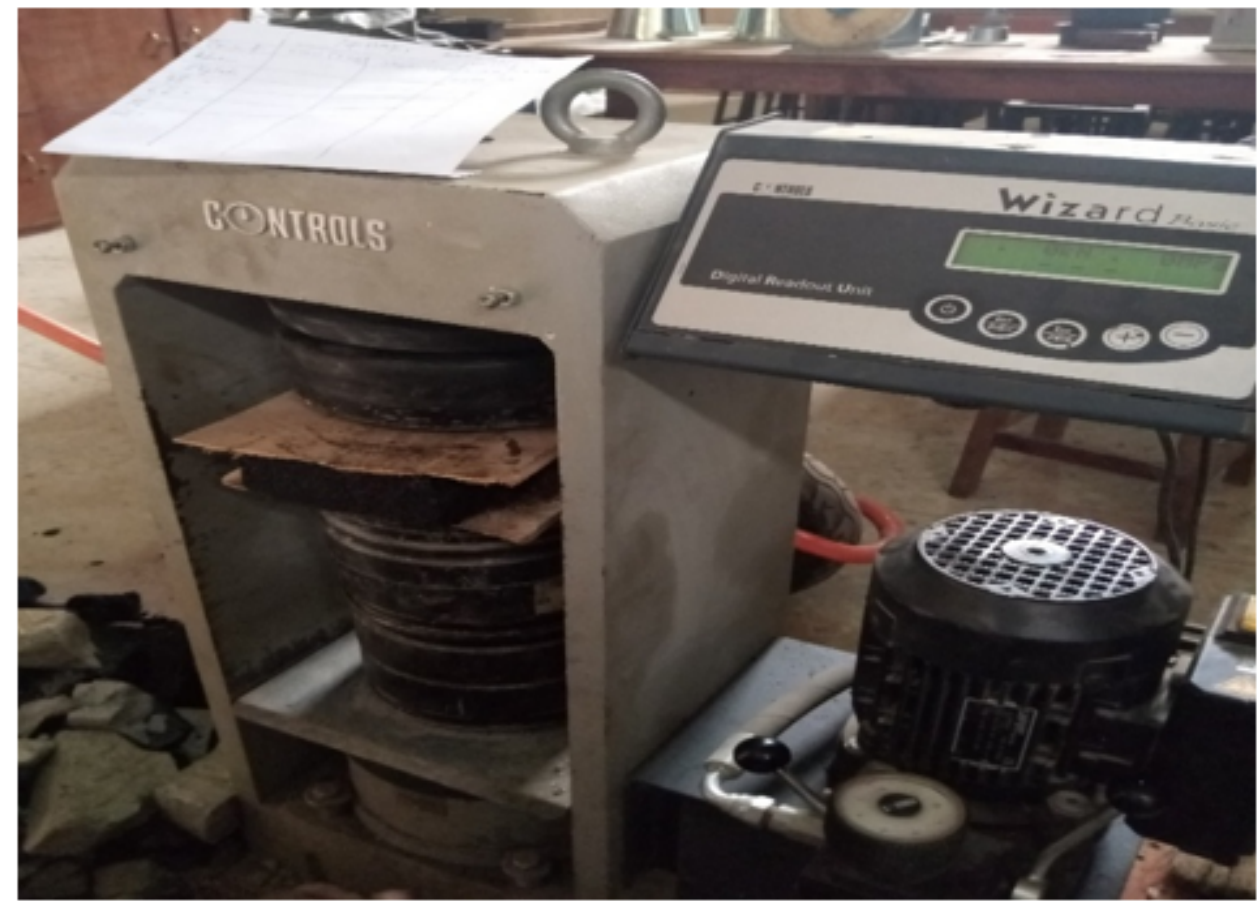

Figure 2 
Compressive Strength Measurement of Paving block

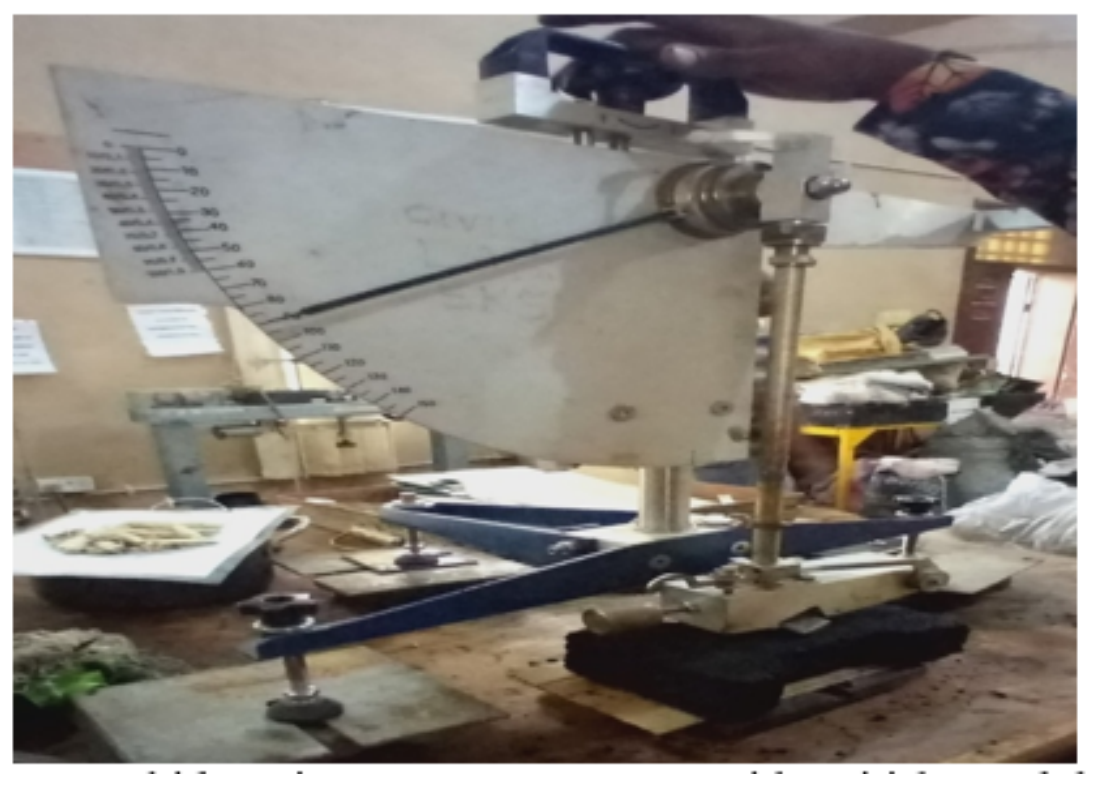

Figure 3

Skid Resistance Measurement with British Pendulum Tester

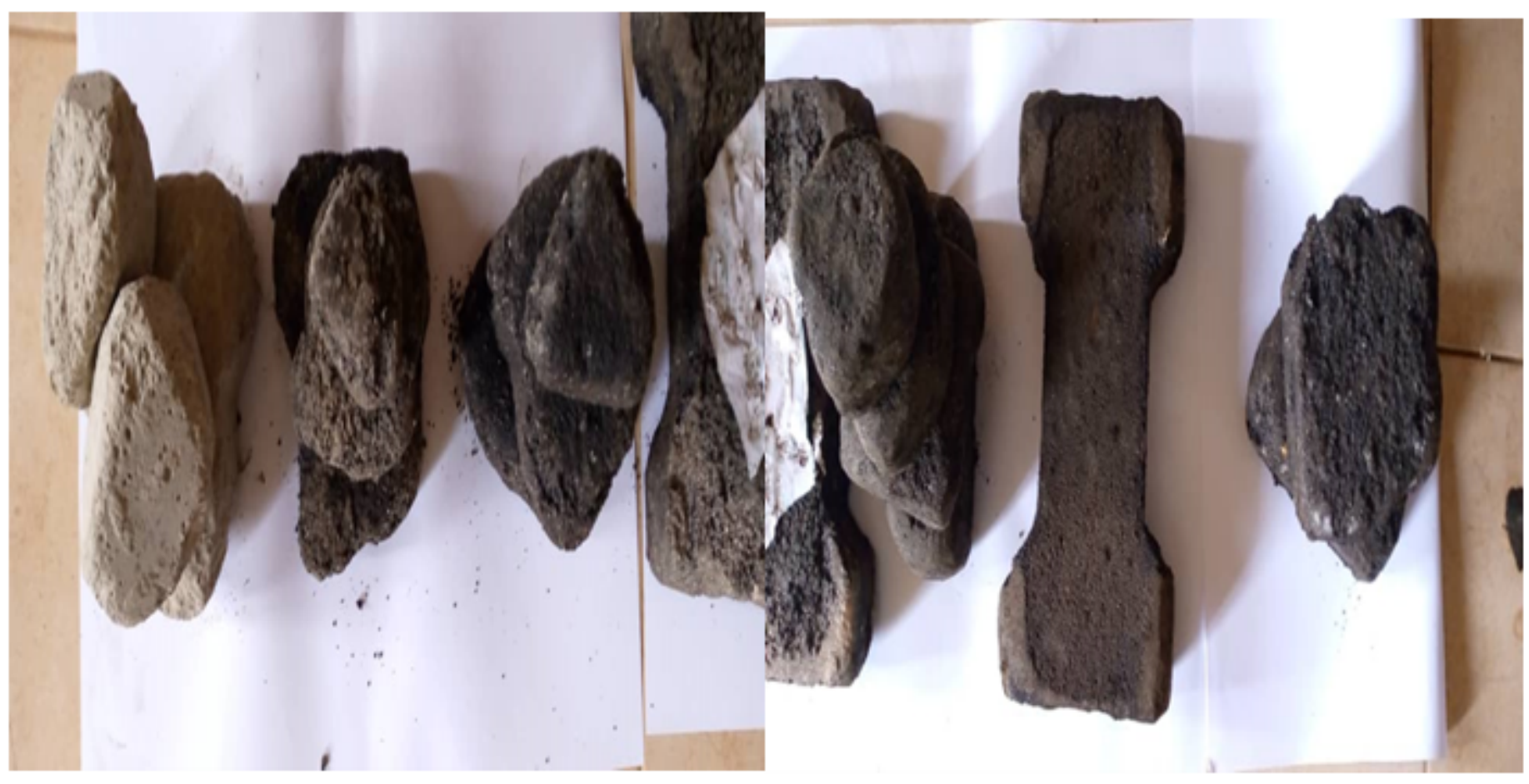

Figure 4

Abraded paving block samples 


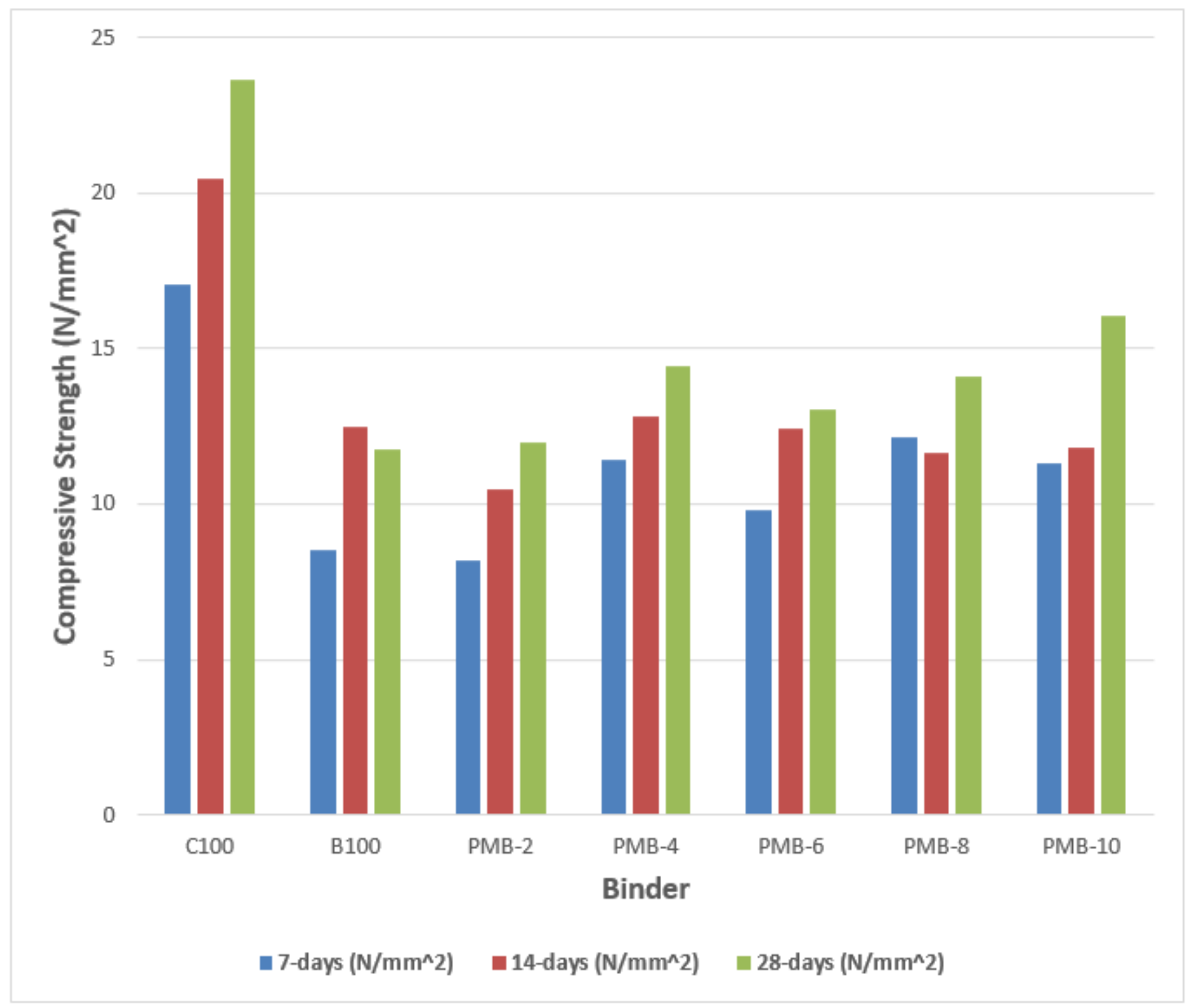

Figure 5

Compressive Strength value for pavement blocks 


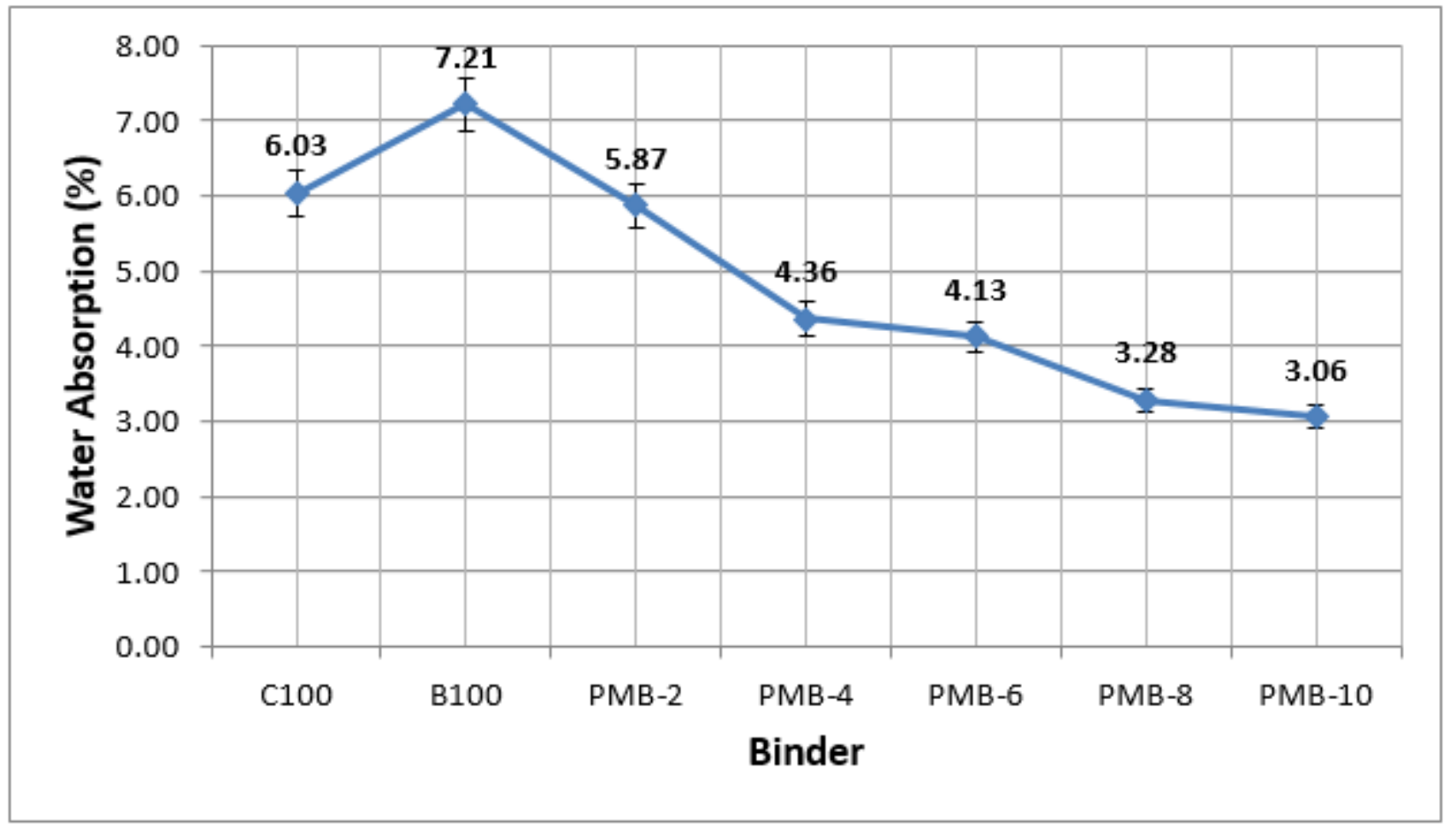

Figure 6

Water Absorption for the pavement blocks

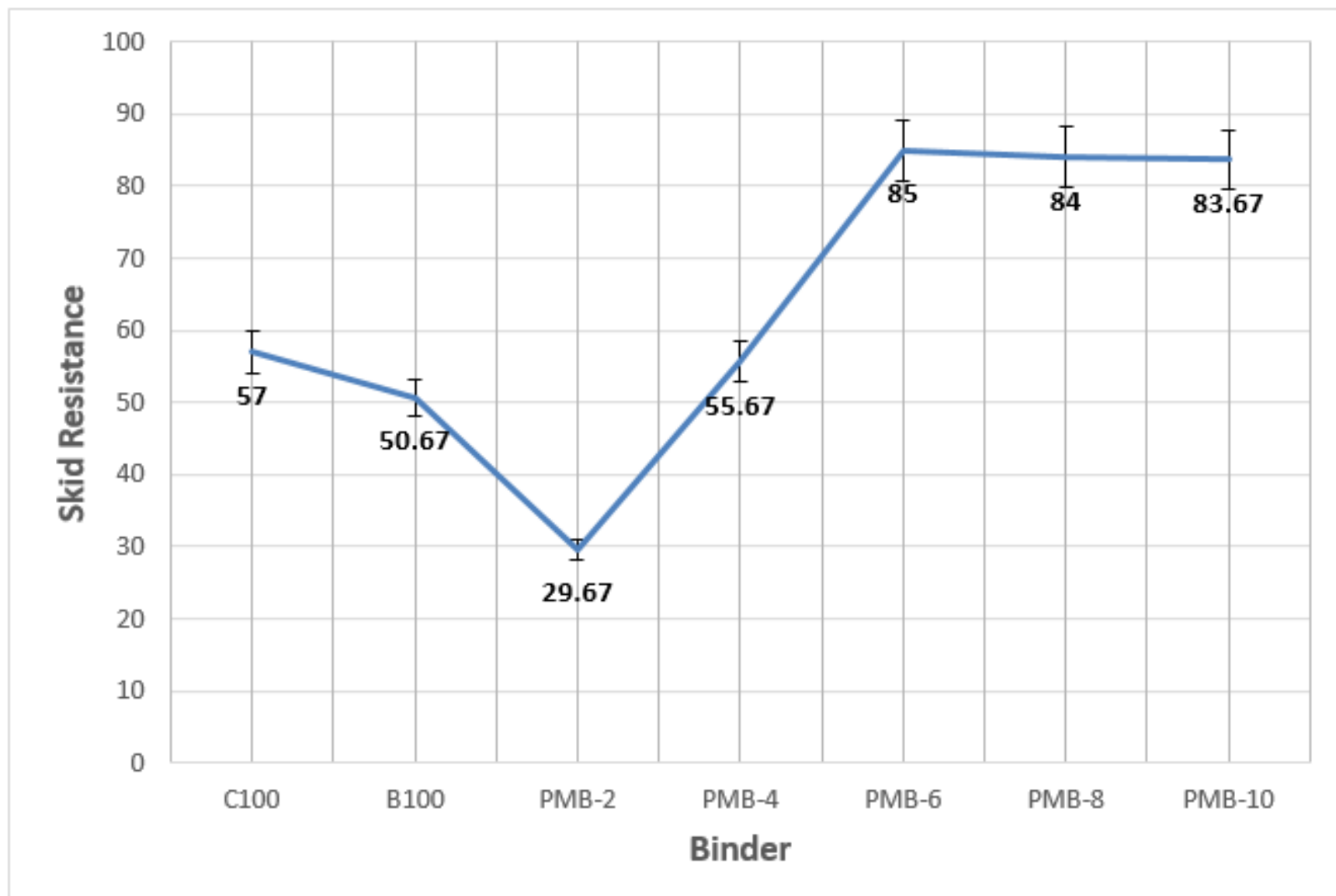

Figure 7 
Skid resistance for pavement blocks with different binder content

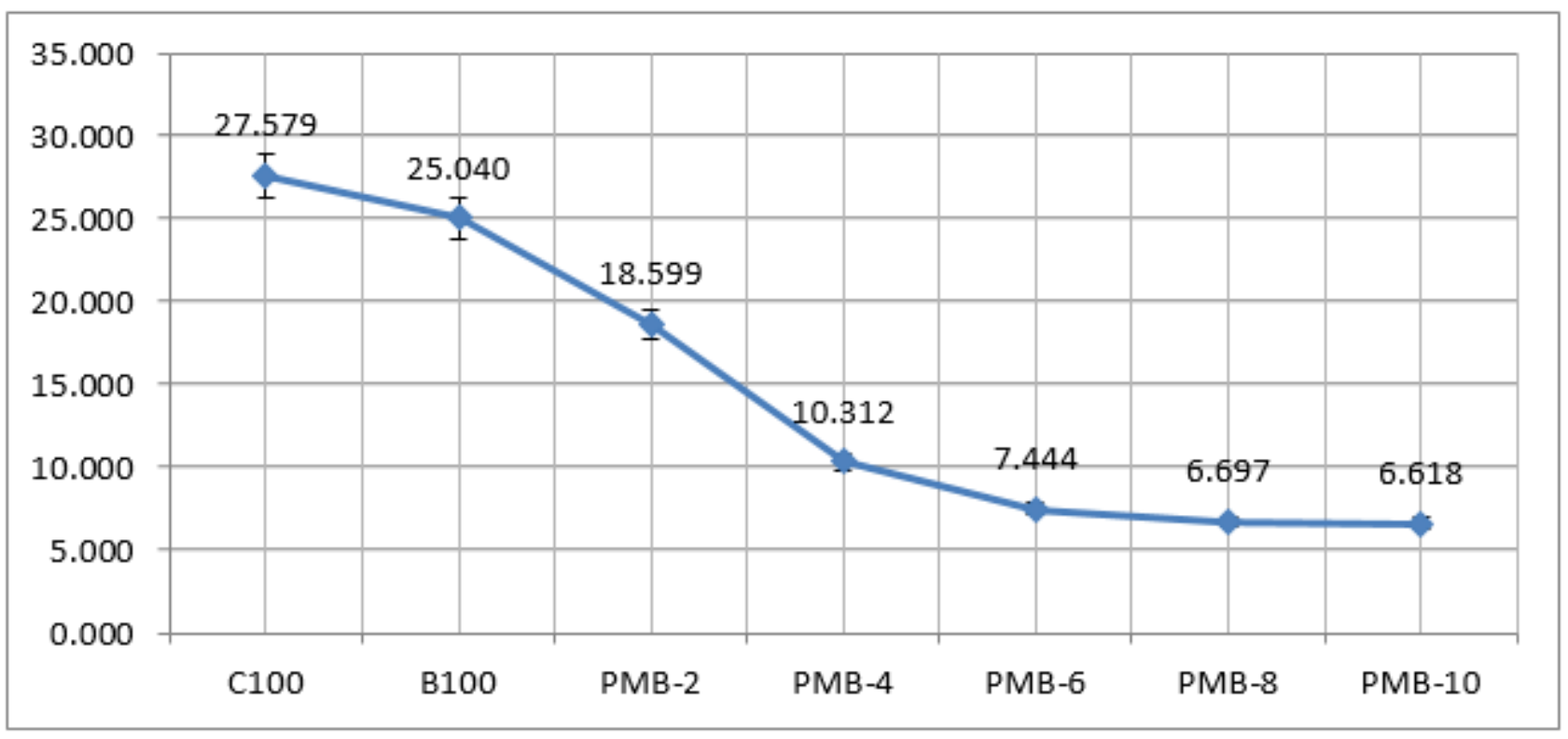

\section{Figure 8}

Cantabro abrasion loss for different binder composition

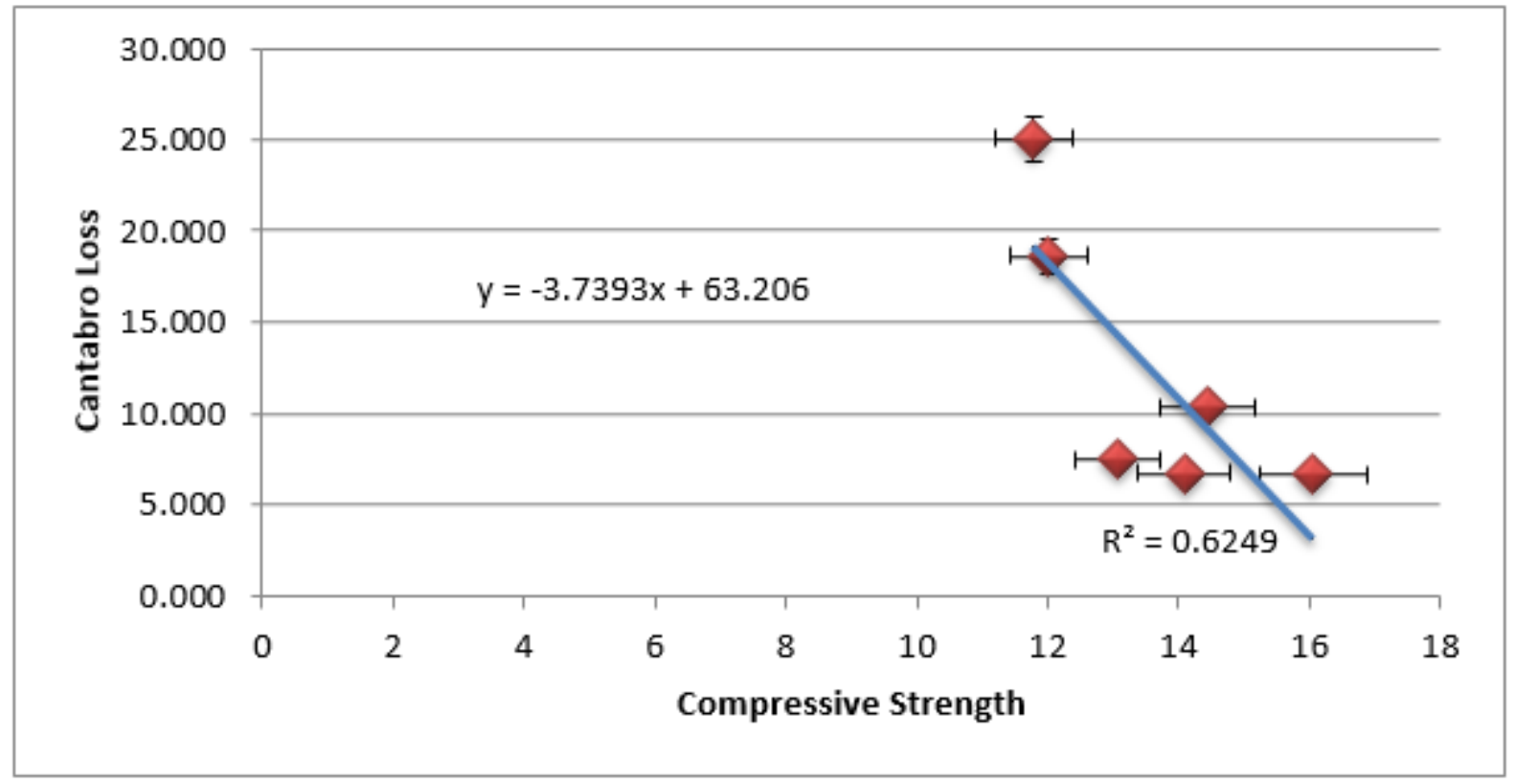

\section{Figure 9}

Relationship between Cantabro loss and Compressive Strength 